\title{
Negligence, genuine error, and litigation
}

This article was published in the following Dove Press journal:

International Journal of General Medicine

14 February 2013

Number of times this article has been viewed

\section{David H Sohn}

Department of Orthopedic Surgery, University of Toledo Medical Center, Toledo, OH, USA
Correspondence: David Sohn

Division of Sports Medicine,

Department of Orthopedic Surgery,

University of Toledo Medical Center,

3000 Arlington Avenue, Toledo,

$\mathrm{OH}, 43614$, USA

Tel + I 4193834000

Email david.sohn@utoledo.edu
Abstract: Not all medical injuries are the result of negligence. In fact, most medical injuries are the result either of the inherent risk in the practice of medicine, or due to system errors, which cannot be prevented simply through fear of disciplinary action. This paper will discuss the differences between adverse events, negligence, and system errors; the current medical malpractice tort system in the United States; and review current and future solutions, including medical malpractice reform, alternative dispute resolution, health courts, and no-fault compensation systems. The current political environment favors investigation of non-cap tort reform remedies; investment into more rational oversight systems, such as health courts or no-fault systems may reap both quantitative and qualitative benefits for a less costly and safer health system.

Keywords: medical malpractice, tort reform, no fault compensation, alternative dispute resolution, system errors

\section{Introduction}

Everyone wants a safer medical system. Each year, thousands of medical errors are made, resulting in injuries to patients who may deserve compensation. ${ }^{1}$ The challenge, however, is to design a system that compensates injury, correctly identifies medical error, and learns from adverse events to build systems that eliminate errors. In this paper, the author will (1) discuss the differences between adverse events, negligence, and system errors; (2) discuss the current medical malpractice tort system; and (3) review current and future solutions, including medical malpractice reform, alternative dispute resolution (ADR), health courts, and no-fault compensation systems.

\section{Adverse events, negligence, and system errors Adverse events vs negligence}

It is important to understand one fundamental concept - there is a difference between adverse events and negligence. An adverse event is an injury occurring during the course of medical management. ${ }^{1}$ For example, Patient A has pneumonia and is prescribed Antibiotic X. The patient develops an unforeseeable allergic reaction to Antibiotic X, causing short-term kidney failure and hospitalization. This kidney injury is an adverse advent. This is not, however, negligence. Negligence is the failure to provide a standard level of care or, in other words, the delivery of substandard care. In the above scenario, it would have been negligence if the physician had neglected to check the chart, which stated that Patient A was allergic to Antibiotic X. 
Many adverse events occur in the practice of medicine, but relatively few are due to negligence. For example, a Harvard Public Health Study estimated that only $27 \%$ of adverse events were due to negligence. ${ }^{1}$ Medicine is not an exact science, and complications are an inherent feature of any procedure or medical intervention. For example, surgical procedures generally carry a $3 \%-4 \%$ risk of infection. Sterile techniques, preoperative cleansing, and prophylactic antibiotics are all used in an attempt to minimize infection. Nonetheless, even in the most capable hands and under the best of circumstances, infection can occur. This would be an adverse event, but not one due to a medical error. It would instead be a risk inherent in the practice of medicine. Similarly, pneumonia may result in a patient's death despite him receiving the proper antibiotics, blood clots may develop despite administration of proper anticoagulation agents, and nerve injuries may result despite properly performed procedures.

It is important to differentiate between adverse events and medical errors, because punishing adverse events per se would have a chilling effect on treating complex conditions or performing difficult procedures, ${ }^{2-4}$ such as liver transplants or neurosurgery. It would also discourage care of high-risk patients with multiple comorbidities. An ideal oversight system would, therefore, not punish adverse events, but rather identify and target medical errors.

\section{System errors versus negligence}

Another important concept to understand is the difference between negligence and system error. Negligence, as discussed above, is failure to meet a standard level of care. It is an incorrect decision. For example, it is considered negligent if the standard of care for kidney failure is dialysis, and this is not ordered. A system error, on the other hand, is an occasional, simple human error. Deterrents cannot reduce these errors, because they are made unintentionally. From time to time, humans unwittingly make errors, such as mistaking salt for sugar when baking, mistaking an oxygen tank for a nitrogen tank during airplane maintenance, or mistaking " $1.5 \mathrm{mg}$ " for " $15 \mathrm{mg}$ " or " $15 \mu \mathrm{g}$ " when administering medication. This is not a decisional error, and so is not negligence. It is considered a system error because good organizations recognize the human error component and safeguard against it. Health care providers misread handwriting occasionally because they are human; however, a good system could reduce system errors by instituting computerized medication orders. Another example of a system safeguard is the use of ID bracelets to prevent confusion between patients with similar names.
According to a landmark 1999 Institute of Medicine paper, To Err is Human, most medical errors are the result of unavoidable human error, which can only be reduced through system changes. ${ }^{5}$ Punishment for errors will not reduce future errors, to ensure a safer system. It might, however, incentivize workers to hide rather than report these errors. An analogy is made to the airline industry; the operation of a health care system is similar to running an airport. In both cases, many people work together toward a common goal, and the best systems are those that acknowledge that, due to the human element, there will be occasional errors. Accordingly, the best systems will implement checks and rechecks in order to catch and contain these errors. For example, even if they are diligent, airline workers might occasionally mistake an oxygen tank for a nitrogen tank. It is not effective to punish workers for making these errors, as they are not the result of laziness or negligence, but are simply mistakes that people may make. A better solution would be to use different couplers for the two gases, so that a nitrogen tank could not be hooked up in place of an oxygen tank. The safest systems are those that acknowledge human error and build in safeguards on a systemic level.

Negligence is actually rarely present in most alleged cases of medical malpractice. ${ }^{6}$ In one study in New York, adverse events were reported in $3.7 \%$ of all hospitalizations. In over $70 \%$ of these cases, ${ }^{1}$ however, no negligence was present. In another closed claim study performed at Harvard, only $15 \%$ of medical malpractice cases actually contained negligence. ${ }^{6}$ And in a 2005 Congressional Report, over $80 \%$ of malpractice cases reviewed actually contained no negligence. ${ }^{8}$ One explanation for this is that health care providers, from medical assistants to nurses to physicians, tend to be highly motivated individuals. ${ }^{5}$ Rather than being motivated by money, most health care practitioners tend to be motivated by professional or moral ideals to deliver high quality care and to "do no harm." As such, negligence is not usually at the heart of most medical errors.

It is important to differentiate between system errors and negligence errors to identify those errors that can be deterred through the legal system (negligence) and those errors that can be reduced only with system safeguards (system errors). A rational oversight system will devote more energy towards preventing the more commonly made errors.

\section{The current medical malpractice tort system}

Currently, in the United States, medical errors are prosecuted under the tort system. The tort system seeks to deter 
negligence by monetarily punishing negligent providers and compensating the injured parties with those monies. According to Prosser and Keeton on Torts the goals of the litigation system are to (1) compensate plaintiffs injured by negligence; (2) discourage the practice of negligence; and (3) exact corrective justice. ${ }^{9}$ A classic application of the tort system is deterrence of known product dangers by corporations. For example, if ABC Motor Company has knowledge that a gas tank is positioned in a precarious location, and yet chooses to continue production of this vehicle, injured parties will likely sue ABC Motor Company for their negligent practice. If a verdict is issued in favor of the plaintiffs, the goals of tort will be served. The plaintiffs will be compensated for their injuries, $\mathrm{ABC}$ will be deterred from similar future negligent behavior, and justice will be served, at least monetarily.

Some important limitations must be understood here. First, the litigation system can only deter negligence and compensate patients for injuries attributable to negligence. This means that the majority of patients experiencing adverse events will have no recourse through the litigation system. Consider that only $27 \%$ of adverse events occur through medical error, and that only a fraction of those medical errors are attributable to negligence, and it is quickly apparent that very few patients who experience adverse events will be entitled to compensation. ${ }^{1}$ This, however, does not prevent them from suing. Many patients sue when there is injury, failing to understand the fundamental differences between an adverse event and a medical error, or the difference between system errors and true negligence. The result is an overwhelming amount of time and money spent on fruitless litigation that serves neither to compensate the injured patient nor to improve the health care system. Over $60 \%$ of all filed lawsuits in medical malpractice cases end up summarily dismissed as having no grounds to even have been filed in the first place. ${ }^{4}$ And, according to a claim trend analysis from malpractice insurers, less than $1 \%$ of all filed medical malpractice claims actually end up in a verdict for the plaintiff. ${ }^{10}$ Even in these cases, most of the award is actually consumed by the attorney and administrative costs. ${ }^{7,11}$ So of the $\$ 76$ to $\$ 126$ billion spent each year in the United States on medical malpractice litigation, ${ }^{12}$ very little actually ends up truly compensating the patient. In other words, litigation is expensive and inefficient.

Second, the medical field is different from the business world. Most business decisions are driven by a cost-benefit analysis. Without the threat of lawsuits, it is possible that a cost-benefit analysis would favor the introduction of marketable yet unsafe products. The tort system in such situations helps create a safer society by increasing the "cost" side of the analysis, and discouraging the production of unsafe products. Health care providers, however, are not trained to engage in cost-benefit analysis. Rather, physicians are driven by professional ethics to first "do no harm" and second to heal the patient. According to the 1999 Institute of Medicine report, To Err is Human, physicians as a group are already ethically motivated to avoid negligent behavior, and the threat of litigation does not add to this motivation. Instead, litigation has a negative effect on physician behavior. On a personal level, it creates an environment of fear and anxiety, disrupting the physician-patient relationship and causing physicians to fear patients as potential litigants. On a societal level, litigation causes physicians to practice defensive behaviors and avoid offering high-risk services, such as obstetrics or neurosurgery. Both situations are undesirable.

A more rational system would focus more on the goals of compensation and improvement, rather than on punishment for those who err. Reform efforts have been largely focused on trying to make the medical malpractice system more efficient. The main goal over the past 30 years has been to eliminate frivolous lawsuits, either by reducing the incentive to sue or by making it less likely for an unfounded suit to prevail.

\section{Recent reform efforts Caps on noneconomic damages}

The first generation of tort reform efforts began in the mid-1970s, with the placement of caps on noneconomic damages in medical malpractice cases. Caps on noneconomic damages are monetary limits on the amount of money that can be awarded by a jury for injuries that are not economic in nature. Economic damages are damages that are readily calculated, such as medical expenses or lost wages. For example, if a patient whose salary is $\$ 50,000$ per year loses three working years to injury, the lost wages are $\$ 150,000$. This is an economic injury, and there is no limit or cap on this type of economic damage. Noneconomic damages are much more difficult to calculate, and therefore, more contentious in court. It is difficult, for example, to place a dollar value on "pain and suffering" or "loss of consortium" with a spouse. From a trial lawyer's perspective, much of the value of a case comes from the noneconomic damages. There are two reasons for this. First, lawyers often work on billable hours. A trial lasting three years, therefore, will generate more fees than a trial lasting only one year. Gray or nebulous items are 
often fought over for long periods during trial, so difficult terms, such as "pain and suffering," naturally extend the life of a trial. Indeed, a RAND corporation analysis of cases before and after implementation of caps on noneconomic damages shows that trial times were reduced from three years to one year after implementation of caps in California. ${ }^{13}$ In other words, noneconomic damages generate increased attorney fees. Second, the potential value of the case is greater with noneconomic damages. When a lawyer assesses a case, the potential value of the jury verdict is calculable before the decision to pursue litigation. An infected total knee case might be thought of in terms of medical expenses for treatment of the infection $(\$ 10,000)$, as well as the months of lost wages while the patient is recovering from the infection $(\$ 40,000)$. The economic damages in this case would be $\$ 50,000$. The noneconomic damages, however, are unknown, and could be argued to an unlimited level. A lawyer might demand, for example, $\$ 1$ million for the pain and suffering of having to undergo further treatment, or not being able to consort with a spouse during the second recovery period. Suddenly, the value of each and every adverse event, whether with merit or not, is potentially high enough to seek litigation.

Caps on noneconomic damages originated in 1975, when the State of California was undergoing a medical malpractice crisis. A boom in the value of jury verdicts in medical malpractice fueled a spate of litigation against doctors for adverse events. This, in turn, raised malpractice insurance premiums. In some cases, physicians could no longer afford malpractice insurance, and closed their practices. In other cases, insurers themselves decided that physicians were too risky to insure, and terminated coverage. The end result was the loss of thousands of physicians from the health care workforce, which threatened California citizens' access to care. An emergency session of the California legislature convened to address the problem, resulting in the passing of the Medical Injury Compensation Reform Act (MICRA). This law instituted a cap of $\$ 250,000$ on noneconomic damages in medical malpractice cases. The results were dramatic. Increases in malpractice premiums slowed to one-fourth of that of the rest of the nation. Trials were settled in one-third of the time, which ironically led to more money for the plaintiffs, as billable hours for attorneys sharply decreased. ${ }^{13}$ And, most interestingly, physicians actually ordered fewer tests and procedures. Overall medical expenditure decreased between 5\% and 9\%. ${ }^{14}$ According to Stanford economists, implementation of caps on a national level would result in savings on such defensive medicine by $\$ 83$ to $\$ 151$ billion per year. $^{14}$
Caps, however, are not a complete solution. The central flaw of the litigation system is that it can only deter negligence. Since the overwhelming majority of medical injuries are not based in negligence, the impact of litigation reducing adverse events is necessarily limited. Caps on noneconomic damages may limit some of the inefficiency and waste of the litigation system, but they are still based on litigation. Similarly, caps do not make a safer system, just a less expensive one. Second, the widespread implementation of caps are likely not feasible politically. Caps on noneconomic damages are vigorously opposed by trial lawyer political action committees, which have given over $\$ 30$ million to politicians to oppose caps on a national level. While caps have been passed in places at a state level, such as in California, Texas, and Ohio, on a federal level, they have been consistently blocked. ${ }^{15}$ In 2003, a national cap on noneconomic damages bill was supported by a Republican-controlled House of Representatives and a Republican President, but was thwarted by a unanimous block of Democratic Senators. More recently, the Patient Protection and Affordable Care Act (PPACA), despite recommendations from the Congressional Budget Office ${ }^{16}$ and a President Obama-appointed health care committee ${ }^{17}$ to include caps, was not. In fact, an earlier version of PPACA actually contained a protection clause for attorney fees. This has left many observers feeling that while effective, caps may not be a politically feasible means of effecting widespread tort reform.

\section{Alternative dispute resolution}

The second generation of tort reform involves ADR, which refers to any of a number of dispute resolution techniques that help plaintiffs and defendants resolve conflicts outside of the courtroom. One advantage of ADR is that it is better suited to adverse events than is the tort system. Litigation can only compensate patients who are harmed by negligence. ADR can potentially reach all patients who experience adverse events, whether due to negligence or not. For example, many hospitals have embraced "early apology" programs, where physicians and hospital administrators reach out to the injured patient and express sympathy about the adverse event. This protects the natural physician-patient relationship as well as encourages dialogue. Perhaps the adverse event was simply a known complication, which may be relayed to the patient who can then save time and focus their efforts on healing rather than pursuing litigation. Perhaps the adverse event was the fault of the physician; in such cases, both parties can agree early on that the physician was at fault and use time and money that would have otherwise been spent on 
contentious litigation (most of which would go to attorneys) and divert the money to the plaintiff directly. Or perhaps the adverse event was the result of unavoidable human error, and investment in system safeguards needs to be made to avoid future events.

The most popular ADR techniques are mediation and arbitration, which differ in both their binding nature and their formality. Mediation is simply negotiation that is aided by an impartial mediator. It is non-binding, meaning that if a settlement cannot be reached, the plaintiff may pursue his claim in court. Arbitration is more involved. It is more court-like, with an arbiter hearing both sides much like a judge would. Similarly, there are rules for how and when to talk, and how to present evidence. Most importantly, it is binding, meaning that the judgment of the arbiter is final and litigation is not an option.

Mediation has had excellent success where implemented, both in terms of cost-containment and satisfaction for both parties. Two notable success stories include the mediation programs at Drexel and the University of Pittsburgh. They have reported $85 \%$ and $88 \%$ successful resolution of conflicts without litigation, respectively. In the case of the University of Pittsburgh, this led to an estimated savings of $\$ 1$ million in the first year of implementation alone. ${ }^{18}$ Mediation also boasts over $90 \%$ satisfaction from both parties. ${ }^{19}$ From the plaintiff's perspective, mediation offers more flexibility than litigation, which only offers money as a remedy. For example, rather than just receiving money, plaintiffs may wish for a scholarship to be established in their family's name, or would like their deceased's story told to incoming nurses or medical students to help prevent similar adverse events in the future. Mediation often suits plaintiffs' needs better, as many sue for nonmonetary reasons, such as the desire for disclosure of information or the desire to hear an apology or explanation of what went wrong. In one survey of plaintiffs, money was actually tertiary to these concerns. ${ }^{19}$ These very aspects, however, are often withheld in a litigious environment.

Arbitration, on the other hand, is more acrimonious and expensive, being more trial-like than mediation. Arbitration is longer and more expensive than mediation, but much shorter and less expensive than jury trials. ${ }^{18-24}$ Like jury trials, they can only offer money as a form of redress, eliminating the more creative and satisfying solutions offered in mediation. Furthermore, arbiters are criticized by plaintiffs and defendants alike for always seeking compromise, rather than justice. ${ }^{24}$ For example, even in a case where there is no negligence, arbiters tend to offer something to the plaintiff, just for the sake of compromise. However, arbiters do boast $100 \%$ avoidance of litigation, making arbitration very appealing to malpractice insurers and hospital systems, as even a successful defense can cost close to $\$ 100,000 . .^{25}$ One increasingly popular form of arbitration is the pretreatment arbitration agreement, where patients agree to arbitration as a condition of being seen in the first place. Although these have withstood early legal challenge ${ }^{26}$ caution is advised before engaging in pretreatment arbitration agreements. First, it may be awkward to discuss adversarial postures during the initial physician-patient visit. Second, it may actually be in the physician's favor to preserve the right to a jury trial. The fact that mediation is non-binding is probably more advantageous to the physician defendant than to the plaintiff. Because the majority of lawsuits actually do not involve negligence, many physicians who are sued wish for the opportunity to clear their name. Jury trials, after all, overwhelmingly result in verdicts for the physician. ${ }^{25}$ They may be forced, however, by their insurance carrier to accept a settlement, which may be less expensive and less risky than a jury trial. This not only may be offending to an innocent physician, but may have real repercussions, as all settlements are mandatorily reported to the National Practitioner Data Bank (NPDB). This affects future medical malpractice rates and the ability to obtain practicing privileges in other states or hospitals.

Another advantage of ADR is that, unlike caps on noneconomic damages, it is politically feasible. Neither trial lawyers nor politicians oppose ADR. In fact, PPACA, while not containing any tort reform itself, does allocate $\$ 50$ million for research into non-cap remedies for medical malpractice reform. This would include ADR.

The main obstacle to ADR implementation is the mandatory reporting requirement of the NPDB. The NPDB, as discussed above, records any settlement involving a physician. This, however, has a chilling effect on the use of settlements. Consider a case where a patient develops a blood clot and dies after a total hip arthroplasty, despite proper anticoagulant use. There is no negligence in this case, but it is still an adverse event, and both hospital and physician may wish for compensation for the family. To do so would be an admission of guilt, since a settlement would be recorded against the physician in the NPDB. Thus, the physician may actually prefer to be sued, win the case, and have nothing recorded against him. This, however, would cost time and money, and result in no compensation for the patient's family. One possible solution to this problem would be to create an 
exception to the mandatory NPDB reporting requirement, where reporting of non-negligent settlement agreements are not required.

\section{Health courts}

Health courts are specialized tribunals where medical malpractice cases would be decided by medically savvy judges or tribunals rather than juries. They would be similar to Workman's Compensation courts, which take normal injury claims out of the tort system and put them into the administrative system. The concept of health courts has recently been revived by the Harvard School of Public Health as a means of deterring frivolous litigation and preventing miscarriages of justice. ${ }^{27}$ One problem for juries is that they can be confused by the difference between adverse events and negligence. Part of this may be due to the scientific questions involved in a medical case, and part of it may be due to the tendency of a jury to be overly swayed by a patient who invites sympathy. Consider, for example, the medical condition of cerebral palsy. Cerebral palsy is a developmental disorder with a varied spectrum of mental and physical impediments. Sometimes a cerebral palsy patient is so impaired that he is wheelchair bound, incapable of speech, and totally dependent on others for activities of daily living. Such a condition may be sympathy-evoking, but may not be caused by birthing trauma. According to a joint study by the American Academy of Pediatricians and the American College of Obstetricians and Gynecologists, the "vast majority" of cerebral palsy cases originate in utero, well before childbirth. One trial lawyer in North Carolina, however, was very successful at confusing jurors about the true underlying medical issues, focusing their attention instead on the plight of the patients and their burdened families, and won over 30 multimillion dollar verdicts, including one \$23 million judgment for what is essentially a naturally occurring and unpreventable condition. ${ }^{3}$ Health courts would likely not be swayed by such tactics, and knowing this, even unethical trial lawyers would likely not invest their time in such frivolous lawsuits. This would reduce the burden of litigation on the medical system, and perhaps (similar to caps on noneconomic damages) reduce the amount of defensive medical expenditure.

Another advantage of health courts are that, like ADR, they are politically feasible. Health courts have already been specifically and publicly endorsed by both Democrats and Republicans. ${ }^{28}$ President Obama, who resisted even his own health care committee's recommendation ${ }^{17}$ for caps as a means of significant national savings, has already appropriated $\$ 50$ million for investigation into health courts. ${ }^{29}$
The main obstacle to implementation of health courts is legal theory. Several constitutional issues have been raised about the legitimacy of health courts ${ }^{30}$ based on constitutional rights to jury trial and claims that creation of such courts overreach Congressional power. These claims have not been worked out specifically for health courts, but the recent Supreme Court decision regarding PPACA likely extrapolates authority for Congress to create health courts through the Commerce Clause. And, similar to Workman's Compensation, there likely is enough of a public interest in swift and expert adjudication of medical malpractice issues to remove them from jury trials. However, these issues still have to be adjudicated.

\section{No-fault compensation}

Several countries overseas have taken the administrative question one step further, and created no-fault compensation schedules for medical malpractice injuries..$^{31}$ New Zealand, Sweden, and Denmark have replaced litigation altogether with administrative compensation systems, where patients who sustain an avoidable medical injury can apply directly, without an attorney, for compensation. An expert medical panel reviews the case and decides on compensation. There are two enlightened features in these systems. First, compensation can be given to the injured parties even without finding fault or negligence. This immediately broadens the scope of patients who are entitled to compensation, a fundamental improvement over negligence. Second, information from claims is used to analyze opportunities for system improvements. Thus, there is an acknowledgement that most medical errors are actually system errors, as well as the determination of mechanisms to seek system improvements. In this way, no-fault compensation systems are the most rational compensation systems currently available: there is acknowledgement that most adverse events are not the result of negligence, so compensation is not tied to finding of fault; there is an inherent understanding that most errors made in medicine are system errors, which allows the oversight system to actually flow into efforts to create safer systems; and both juries and attorneys are eliminated from decision making, leading to more expert adjudication and more efficient delivery of compensation to the actual plaintiffs.

Two foreseeable obstacles remain in the implementation of no-fault compensation. First, the same legal legitimacy objections raised against health courts would likely be raised against no-fault compensation systems. Second, these may prove to be politically non-feasible. If trial lawyer interests vigorously oppose caps on damages, they would certainly oppose removal of attorneys altogether from the medical malpractice oversight system. Still, there may be precedents 
that mitigate both arguments. Several states have instituted no-fault compensation systems in the arena of automobile accidents, removing these from the tort system altogether. Even if Motorist A is completely at fault for damaging Motorist B, Motorist B may not sue for damages in some states simply because these states wished to clear these cases from the administrative dockets of their courtrooms. A much stronger public interest exists in removing medical malpractice cases from tort to no-fault compensation schedules for plaintiffs, health care practitioners, and society as a whole. Plaintiffs gain because a wider group of patients can find compensation, a greater percentage of funds can go to the actual parties, and claims are processed faster than with litigation. Physicians gain because they are not being sued and can focus on providing better care rather than engaging in defensive practices. The nation gains because data can be collected to identify system shortcomings to build safer systems, rather than spending over $\$ 100$ billion $^{12}$ per year on litigation that mostly goes to attorneys.

\section{Summary}

Only a fraction of medical injuries actually arise from negligence. Most injuries either result from system errors, or are inherent risks in the practice of medicine. Compensation for such injuries, therefore, cannot rationally come from the tort system, which compensates only for errors arising from negligence. A more rationale form of compensation would move away from blame-based systems, such as tort and medical malpractice, which are costly and inefficiently compensate patients, and would instead move toward more compensation-based systems, such as ADR and no-fault systems. The current political environment favoring investigation of non-cap tort reform remedies, and investment into more rational oversight systems, such as health courts or no-fault systems, may reap both quantitative and qualitative benefits for less costly and safer health systems.

\section{Disclosure}

The author reports no conflict of interest in this work.

\section{References}

1. Brennan TA, Leape LL, Laird NM, et al. Incidence of adverse events and negligence in hospitalized patients: results of the Harvard Medical Practice Study I. 1991. Qual Saf Health Care. 2004;13:145-151; discussion 51-52.

2. Thornton T, Saha S. The need for tort reform as part of health care reform. J Long Term Eff Med Implants. 2008;18:321-327.

3. Edwards' malpractice suits leave bitter taste. The Washington Times. August 16, 2004. Available at http://www.washingtontimes.com/ news/2004/aug/16/20040816-011234-1949r/?page=all\#pagebreak.
4. Weinstein SL. Medical liability reform crisis 2008. Clin Orthop Relat Res. 2009;467:392-401.

5. Kohn LT, Corrigan JM, Donaldson MS. To Err is Human: Building a Safer Health System. Washington, DC: Institute of Medicine; 1999.

6. Weiler PC. A measure of malpractice: medical injury, malpractice litigation, and patient compensation. Cambridge, Mass.: Harvard University Press; 1993.

7. Localio AR, Lawthers AG, Brennan TA, et al. Relation between malpractice claims and adverse events due to negligence. Results of the Harvard Medical Practice Study III. N Engl J Med. 1991;325:245-251.

8. The Perverse Nature of the Medical Liability System. In: Committee JE, editor. 2005. Available at http://www.house.gove/jec/publications/109/0321-21-05.pdf.

9. Keeton PWP, editor. Prosser and Keaton on Torts, 5th ed: West Publishing, St Paul, MN, USA: 1984.

10. The Physician Insurers Association of America. Claim Trend Analysis; 2004. Rockville, MD, USA.

11. Studdert DM, Mello MM, Gawande AA, et al. Claims, errors, and compensation payments in medical malpractice litigation. $N$ Engl $J$ Med. 2006;354:2024-2033.

12. Confronting the New Health Care Crisis: Improving Health Care Quality and Lowering Costs By Fixing Our Medical Liability System. In: Services UDoHaH, ed. 2002. Available at aspe.hhs.gov/daltcp/reports/litrefm.pdf.

13. Pace NM, Zakaras L, Golinelli D. Capping non-economic awards in medical malpractice trials: California jury verdicts under MICRA. Santa Monica, CA: RAND Corporation; 2004.

14. Kessler D, McClellan M. Do doctors practice defensive medicine? The Quarterly Journal of Economics. 1996;111:353-390.

15. Ballasy N. Howard Dean: Democrats left tort reform out of health care bill because they feared 'taking on' trial lawyers. CNSNewscom. August 26, 2009. Available at http://www.cnsnews.com/node/53126.

16. Congressional Budget Office: Analysis of the effects of proposals to limit costs related to medical malpractice (Tort Reform). [webpage on the Internet]. Available at http://www.cbo.gov/ftpdocs/106xx/ doc10641/10-09-Tort_Reform.pdf.

17. National Commission on Fiscal Responsibility and Reform. [webpage on the Internet]. Available at http://www.fiscalcommission.gov/sites/ fiscalcommission.gov/files/documents/CoChair_Draft.pdf.

18. Creo RA, Shogan JO, Turner CT. Malpractice case alternative dispute resolution. Physician's News Digest. Nov 2005. Available at http://www. physiciansnews.com/2005/11/13/malpractice-case-alternative-disputeresolution/.

19. Szmania SJ, Johnson AM, Mulligan M. Alternative dispute resolution in medical malpractice: A survey of emerging trends and practices. Conflict Resolution Quarterly. 2008;26:71-96.

20. Dauer EA. Alternatives to litigation for health care conflicts and claims: Alternative dispute resolution in medicine. Hematology/Oncology Clinics of North America. 2002;16:1415-1431.

21. Fraser JJ Jr. American Academy of Pediatrics: Technical report: Alternative dispute resolution in medical malpractice. Pediatrics. 2001;107:602-607.

22. Greer TE. Alternative dispute resolution in medical liability cases. AAOS Now. Jul 2009.

23. Metzloff TB. Alternative dispute resolution strategies in medical malpractice. Alaska Law Review. 1992;9:429-457.

24. Rosengard LA, Parker M. Medical malpractice mediation: A "healthy" resolution for patients, doctors and insurance companies. The $A D R$ Advisor. Winter 2010. Available at http://www.stradley.com/newsletters. php?action $=$ view\&id $=524$.

25. Hartwig R. Medical malpractice insurance jury verdict research: Insurance information institute; 2008. Available at http://server.iii.org/yy_obj_data/ binary/729103_1_0/Medmal.pdf. Accessed March 16, 2008.

26. Webb RJ. New Jersey court green lights provider-patient arbitration agreements. Healthcare Neutral ADR Blog. Califon, NJ: Healthcare Neutral, LLC 2010. Available at http://www.healthcareneutraladrblog. com/2010/08/articles/healthcare-arbitration/new-jersey-court-greenlights-providerpatient-arbitration-agreements/. 
27. Mello MM, Studdert DM, Kachalia AB, Brennan TA. "Health courts" and accountability for patient safety. Milbank Q. 2006;84:459-492.

28. Health courts continue to gain bipartisan support from 2012 presidential candidates. New York: PR Newswire 2012. Available at http:// www.prnewswire.com/news-releases/health-courts-continue-to-gainbipartisan-support-from-2012-presidential-candidates-144266955. html.

29. The White House Blog. [webpage on the Internet]. March 2, 2010. Available at http://www.whitehouse.gov/blog/2010/03/02/presidentobama-follows-thursdays-bipartisan-meeting-health-reform- 0 .
30. Widman A, Hochberg FA. Federal administrative health courts are unconstitutional: a reply to Elliott, Narayan, and Nasmith. $J$ Health Polit Policy Law. 2008;33:799-832.

31. Mello MM, Kachalia A, Studdert DM. Administrative compensation for medical injuries: lessons from three foreign systems. Issue Brief (Commonw Fund). 2011;14:1-18.

\section{Publish your work in this journal}

The International Journal of General Medicine is an international, peer-reviewed open-access journal that focuses on general and internal medicine, pathogenesis, epidemiology, diagnosis, monitoring and treatment protocols. The journal is characterized by the rapid reporting of reviews, original research and clinical studies across all disease areas.
A key focus is the elucidation of disease processes and management protocols resulting in improved outcomes for the patient. The manuscript management system is completely online and includes a very quick and fair peer-review system. Visit http://www.dovepress.com/ testimonials.php to read real quotes from published authors.

Submit your manuscript here: http://www.dovepress.com/international-journal-of-general-medicine-journal 